\title{
CC and C chemokine expression in pulmonary sarcoidosis
}

\author{
M. Petrek*, V. Kolek\#, J. Szotkowská*, R.M. du Bois"
}

$C C$ and $C$ chemokine expression in pulmonary sarcoidosis. M. Petrek, V. Kolek, J. Szotkowská, R. M.du Bois. (C) ERS Journals Ltd 2002.

ABSTRACT: The chemokines RANTES (regulated on activation, T-cell expressed and secreted; CC chemokine ligand (CCL)-5) and monocyte inflammatory protein (MIP)$1 \alpha$ (CCL-3) have been implicated in the development of alveolitis in pulmonary sarcoidosis. The novel $\mathrm{C}$ chemokine single cysteine motif (SCM)-1 $\alpha$ (XCL-1) and the CC chemokine monocyte chemoattractant protein (MCP)-1 (CCL-2) are also mononuclear-cell attractants and represent alternative candidate mediators of alveolitis. Therefore, the expression of MCP-1 and SCM-1 $\alpha$ was investigated together with the expression of RANTES and MIP-1 $\alpha$ in bronchoalveolar lavage fluid (BALF) from control subjects and patients with sarcoidosis. The relationship between chemokine expression and sarcoidosis clinical course was also explored.

Messenger ribonucleic acid (mRNA) expression for all four chemokines was determined by semiquantitative reverse transcriptase-polymerase chain reaction of RNA extracted from unseparated bronchoalveolar cells (17 patients, 12 controls). RANTES, MIP-1 $\alpha$ and MCP-1 proteins were measured by enzyme-linked immunosobent assay of unconcentrated BALF (60 patients, 17 controls).

MCP-1, and namely RANTES and SCM-1 $\alpha$ mRNA expression was upregulated in sarcoidosis, particularly in patients with more advanced disease. RANTES, and namely MCP-1 concentrations were elevated in BALF samples obtained from patients; MCP-1 levels were most increased in patients with chest radiographic stage 2 disease and also in patients with persistent and recurrent disease.

In conclusion, chemokines monocyte chemotactive protein-1 and single cysteine motif- $1 \alpha$ are, in addition to RANTES, associated with the development of alveolitis in sarcoidosis and their expression parallels the disease course. Eur Respir J 2002; 20: 1206-1212.

\begin{abstract}
*Depts of Immunology and ${ }^{\#}$ Respiratory Medicine, Palacký University and University Hospital, Olomouc, Czech Republic. Interstitial Lung Disease Unit, Royal Brompton Hospital, London, UK.
\end{abstract}

Correspondence: M. Petrek, Dept of Immunology, Palacký University, IP Pavlova str. 6, 77520 Olomouc, Czech Republic.

Fax: 420585415116

E-mail: petrekm@fnol.cz

\author{
Keywords: CC chemokine ligand \\ lung \\ lymphotactin \\ monocyte chemoattractant protein-1 \\ RANTES \\ $\mathrm{XC}$ chemokine ligand
}

Received: October 262001

Accepted after revision: June 162002

This study was supported by the Czech Ministries of Health (IGA 3768-3) and of Schools, Education and Physical Training (MSM 151100002).
Sarcoidosis is a multisystem granulomatous disorder most frequently affecting the lungs that results from the accumulation of CD4+ T-lymphocytes and macrophages with granuloma formation at disease sites [1]. Although local lymphocyte proliferation occurs in sarcoidosis [2], the alveolitis is largely the result of the recruitment of lymphocytes and monocytes from the circulation to the bronchoalveolar space [3]. This process is characterised by the upregulation of cell adhesion molecules, chemokine ligands and receptors [3, 4]. Chemokines, low molecularweight polypeptides, exert potent chemotactic and activating effects on specific leucocyte populations [5]. With regard to their properties, chemokines are implicated in the development of alveolitis and also sarcoid granuloma formation $[3,4,6]$.

According to their biochemical structure, chemokines are divided into four groups: $\mathrm{CXC}, \mathrm{CC}, \mathrm{C}$ and $\mathrm{CX}_{3} \mathrm{C}$ [3]. Within these broad divisions current nomenclature assigns serial numbers to individual chemokine ligands [7]. The functional properties of RANTES (regulated on activation, T-cell expressed and secreted; CC chemokine ligand (CCL)-5), monocyte inflammatory protein (MIP)-1 $\alpha$ (CCL-3), monocyte chemoattractant protein (MCP)-1 (CCL-2), members of the $\mathrm{CC}$ chemokine group, and also of the $\mathrm{C}$ chemokine single cysteine motif (SCM)-1 $\alpha$ (XC chemokine ligand (XCL)-1) predestine them to mediate mononuclear cell migration to the lungs. RANTES, an in vitro T-cell chemoattractant, preferentially attracts CD45R0+ memory T-cells, which are increased in the lungs of sarcoidosis patients [8]. The chemokines MIP-1 $\alpha$ and MCP-1, originally considered to attract monocytes, have been characterised as potent T-cell attractants in vitro [9]. SCM-1 $\alpha$, human "lymphotactin" [10], is a pure lymphocyte chemoattractant [11].

To investigate the potential role of these "candidate" chemokines in the development of alveolitis in sarcoidosis, the authors have studied chemokine messenger ribonucleic acid (mRNA) and protein expression in bronchoalveolar cells and lavage fluid (BALF) from patients with sarcoidosis and compared them with cells and lavage fluid from control subjects. Further, the authors investigated whether chemokine expression is related to the clinical course of sarcoidosis, as assessed by the chest radiographic stage, the need for treatment and disease resolution/progression. 
Methods

\section{Study population}

In the first part of the study, screening for mRNA chemokine expression was performed in unseparated bronchoalveolar cells recovered from BALF. Bronchoalveolar lavage (BAL) was performed according to a standard protocol in 12 control subjects (age $39.5 \pm 3.8$ yrs (median \pm SEM), seven males, eight nonsmokers, four smokers) and 17 patients with sarcoidosis (age $44.8 \pm 2.2$ yrs, seven males, 16 nonsmokers, one smoker); chest radiograph stage $1(n=12)$, stage 2 $(n=4)$, stage $3(n=1)$. The diagnosis of sarcoidosis was based on typical clinical features together with granulomas on histopathological examination of lung biopsies and was further supported by a lymphocytic CD4+ BAL, and was compatible with the criteria contained in the International Statement on Sarcoidosis [12].

After centrifugation of the BALF, supernatant was obtained and stored at $-80^{\circ} \mathrm{C}$; BALF cell pellets were lysed in guanidine isothiocyanate for subsequent RNA extraction [13]. Of 17 patients with sarcoidosis, $10(59 \%)$ needed corticosteroid treatment, which was always initiated after the lavage. The clinical course ( 2 yrs from the time of presentation) could be evaluated in $15(88 \%)$ patients: five patients $(33 \%)$ recovered without treatment (category 1), six patients $(40 \%)$ recovered after treatment (category 2), four patients $(27 \%)$ had persistent disease (category 3$)$.

The control group consisted of subjects who at the time of presentation and subsequently showed no clinical signs of lung inflammation; they had no lung disease in their medical history. All had normal BALF cytology, immunology and microbiology. In this group, two patients with suspected pulmonary malignancy were included; lavage was performed on an unaffected lobe.

In the second part of the study, chemokine protein expression was investigated in BALF supernatants. Samples were available in 17 control subjects (age 44.6 \pm 4.4 yrs, 13 males, 10 nonsmokers, seven smokers) and 60 patients with sarcoidosis (age 45.5 $\pm 1.5 \mathrm{yrs}, 26$ males, 56 nonsmokers, four smokers); chest radiographic stage $1(n=35)$, stage $2(n=17)$, stage $3(n=3)$ and stage $0(n=5)$. Of 60 patients, $41(68.3 \%)$ required corticosteroid treatment. The clinical course of sarcoidosis ( $2 \mathrm{yrs}$ from the time of presentation) could be evaluated in 54 of $60(90 \%)$ patients: 14 patients $(26 \%)$ recovered without treatment (category 1), 26 patients $(48 \%)$ recovered after treatment (category 2), eight patients $(15 \%)$ had persistent disease (category 3); recurrence of disease was observed in six $(11 \%)$ patients (category 4$)$. The cellular profile of BALF obtained from patients and control subjects is described in table 1 .

All participants (patients and control subjects) were from one referral centre (University Hospital Olomouc, Olomouc, Czech Republic). The study was performed with the approval of the Ethics Committee of this institution.

Assessment of chemokine $m R N A$ expression in $B A L$ cells

Reverse transcription-polymerase chain reaction (RT-PCR) was used to assess chemokine mRNA expression. MIP-1 $\alpha$, MCP-1, RANTES and SCM- $1 \alpha$ mRNA was semiquantified by normalising chemokine expression to the expression of $\beta$-actin: the "chemokine/ $\beta$-actin optical density ratio" (ODR) was calculated for each chemokine mRNA expression in individual subjects. The details on this normalisation approach including results of optimalisation experiments with primer-pairs specific to the investigated chemokines are described elsewhere [13].

\section{Determination of chemokine proteins in $B A L F$}

Chemokine protein levels in unconcentrated BALF were measured using a solid-phase sandwich enzymelinked immunosorbent assay (ELISA). To detect immunoreactive RANTES and MIP- $1 \alpha$, Quantikine assays (R \& D Systems, Abindgdon, UK) were used;

Table 1.-Bronchoalveolar lavage fluid (BALF) cellular profile of patients with sarcoidosis and of control subjects

\begin{tabular}{|c|c|c|c|c|}
\hline & Sarcoidosis patients & Subjects $\mathrm{n}^{\#}$ & Controls & Subjects $n^{\#}$ \\
\hline BALF total cell concentration $\times 10^{5} \cdot \mathrm{mL}^{-1}$ & $2.20(1.60-2.80)$ & 57 & $2.00(1.20-3.25)$ & 15 \\
\hline \multicolumn{5}{|l|}{ BALF differential count } \\
\hline Macrophages $\times 10^{5} \cdot \mathrm{mL}^{-1}$ & $1.59(1.21-1.91)$ & 56 & $1.76(1.14-2.90)$ & 15 \\
\hline Macrophages \% & $72.0(65.0-80.8)$ & 58 & $93.0(91.0-96.0)$ & 17 \\
\hline Lymphocytes $\times 10^{5} \cdot \mathrm{mL}^{-1}$ & $0.53(0.32-0.87)$ & 56 & $0.15(0.04-0.21)$ & 15 \\
\hline Lymphocytes \% & $27.0(17.0-33.0)$ & 58 & $6.0(3.7-9.0)$ & 17 \\
\hline Neutrophils $\times 10^{5} \cdot \mathrm{mL}^{-1}$ & $0.00(0.00-0.03)$ & 56 & $0.00(0.00-0.03)$ & 15 \\
\hline Neutrophils \% & $0.0(0.0-1.0)$ & 58 & $0.0(0.0-1.0)$ & 17 \\
\hline Eosinophils $\times 10^{5} \cdot \mathrm{mL}^{-1}$ & $0.00(0.00-0.00)$ & 56 & $0.00(0.00-0.00)$ & 15 \\
\hline Eosinophils \% & $0.0(0.0-0.2)$ & 58 & $0.0(0.0-0.0)$ & 17 \\
\hline \multicolumn{5}{|l|}{ BALF lymphocyte subpopulations } \\
\hline CD $4+$ cells $\%$ & $64.0(47.0-72.1)$ & 59 & $41.0(30.0-44.0)$ & 13 \\
\hline CD8+ cells \% & $17.0(9.6-24.0)$ & 59 & $32.0(28.0-41.6)$ & 13 \\
\hline CD4+:CD8+ T-cell ratio & $3.70(1.84-7.60)$ & 59 & $1.03(0.88-1.60)$ & 13 \\
\hline
\end{tabular}

The data are presented as median values (1st to 3rd interquartile range). BALF: bronchoalveolar fluid. \#: number of individuals in whom particular data were available. 
the assays showed no cross-reactivity with a range of human chemokines. Briefly, $100 \mu \mathrm{L}$ duplicates of BALF or standards (recombinant human RANTES or MIP-1 $\alpha$ ) were applied to wells of an ELISA tray pre-coated with a mouse monoclonal anti-human RANTES (anti-human MIP-1 $\alpha$ ) antibody. After incubation ( $2 \mathrm{~h}$, room temperature), the wells were washed three times before addition of a horseradish peroxidase conjugated goat-polyclonal anti-RANTES (anti-MIP-1 $\alpha)$ antibody. Trays were incubated $(1 \mathrm{~h}$, room temperature), washed in chromogen and substrate solution (tetramethylbenzidine and hydrogen peroxide, 1:1) added. After incubation (20 mins, room temperature), reactions were stopped by the addition of $2 \mathrm{M}$ sulphuric acid and absorbance was measured at $450 \mathrm{~nm}$ using an ELISA-plate reader (Titertek Multiskan MCC/340, Thermo Labsystems, Vantaa, Finland). The data were processed by KIM-E software (ÚSOL, Prague, Czech Rep.). The lower limit for the detection of RANTES and MIP- $1 \alpha$ was $19.0 \mathrm{pg} \cdot \mathrm{mL}^{-1}$.

MCP-1 protein was measured using a HBT kit (Hycult Biotechnology, Uden, the Netherlands). Briefly, $100 \mu \mathrm{L}$ of duplicate samples or standards (human recombinant MCP-1) were incubated (1 h, room temperature) in wells pre-coated with primary anti-human MCP-1 antibody. After washing, biotinylated secondary antihuman MCP-1 antibody and streptavidin-peroxidase conjugate were added for $1 \mathrm{~h}$. Finally, tetramethylbenzidine substrate solution was applied for $25 \mathrm{~min}$; after stopping the reactions with $2 \mathrm{M}$ sulphuric acid, absorbance was measured at $450 \mathrm{~nm}$. The data were evaluated with KIM-E software; the detection limit of the MCP-1 assay was $6.0 \mathrm{pg} \cdot \mathrm{mL}^{-1}$.

For all three assays, new aliquots of BALF were used to avoid repeated thawing and freezing of the samples, which could diminish chemokine biological activity. SCM-1 $\alpha$ protein was not measured because of the unavailability of an ELISA assay.

\section{Statistical analysis}

The Mann-Whitney U-test was used to detect differences in chemokine mRNA or protein expression between the sarcoidosis and control groups or between patients with distinct diseases stages. Spearman's rank correlation was used to assess the relationship between chemokine expression data and BALF cell counts. A $\mathrm{p}<0.05$ was considered statistically significant.

\section{Results}

\section{Chemokine $m R N A$ expression in BAL cells}

The mRNA for the chemokines RANTES, SCM- $1 \alpha$ and MIP- $1 \alpha$ was present in all BALF cell pellets obtained from patients and controls; MCP-1 mRNA was detected in $88 \%$ (15 of 17) patient samples and $75 \%$ (nine of 12) control samples (fig. 1). Semiquantitative analysis showed significant upregulation of RANTES $(p=0.01)$ and SCM- $1 \alpha(p=0.02)$ mRNA expression in BALF cells from sarcoidosis patients (fig. 1c and d). There was only a trend towards an increased MCP-1 mRNA expression in sarcoidosis patients versus controls (fig. 1a). There was no difference between MIP- $1 \alpha$ mRNA level in patients and controls (fig. 1b).

Chemokine $m R N A$ expression and the clinical severity of sarcoidosis

Chemokine mRNA expression did not differ between the patients with the grade $1(n=12)$ or grade $2(n=4)$ sarcoidosis chest radiographic stages (RANTES mRNA: grade $11.00 \pm 0.26$, grade $21.44 \pm 0.32, \mathrm{p}=0.56$; $\mathrm{SCM}-1 \alpha$ mRNA: grade $12.1 \pm 0.24$, grade $22.00 \pm 0.26, \mathrm{p}=0.76$ ). When disease severity was defined by the need for treatment, based on clinical grounds $(\mathrm{T}+; \mathrm{n}=10)$, there was, however, only a trend towards increased RANTES and especially SCM- $1 \alpha$ mRNA expression at presentation by comparison with patients in whom treatment was not needed (T-; n=5) (RANTES mRNA: $\mathrm{T}+$ $1.48 \pm 0.15, \mathrm{~T}-0.88 \pm 0.63, \mathrm{p}=0.12$; SCM- $1 \alpha \mathrm{mRNA}: \mathrm{T}+$ $2.24 \pm 0.24, \mathrm{~T}-1.56 \pm 0.53, \mathrm{p}=0.06$ ). MCP-1 mRNA expression was also higher in patients with more advanced disease but again the difference was not statistically significant $(\mathrm{T}+0.63 \pm 0.09$, T- $0.40 \pm 0.14$, $\mathrm{p}=0.08)$. MIP-1 $\alpha$ mRNA expression was not related to disease course (data not shown).

\section{Chemokine protein levels in BALF}

Three (MCP-1, MIP-1 $\alpha$, RANTES) of the four chemokines investigated at the mRNA level were explored at the level of immunoreactive protein in unconcentrated BALF fluid; SCM- $1 \alpha$ protein was not measured because of the unavailability of an ELISA assay. While MIP- $1 \alpha$ protein was detected in only one of $77(1.3 \%)$ BALF samples tested, RANTES protein was present in $28 \%$ (17 of 60 ) of patient samples but was not detected in any of 17 of control samples. MCP-1 protein was present in 70\% (42 of 60) of patient samples and in 53\% (nine of 17) of control samples. MCP-1, but not RANTES protein levels, correlated with mRNA expression of given chemokine; correlation coefficient (MCP-1) $\mathrm{r}_{\mathrm{s}}=0.55, \mathrm{p}=0.001$.

MCP-1 BALF protein levels were significantly elevated in patients compared to controls (patients $14.6 \pm 3.5 \mathrm{pg} \cdot \mathrm{mL}^{-1}$; controls $5.7 \pm 2.9 \mathrm{pg} \cdot \mathrm{mL}^{-1} ; \mathrm{p}=0.02$ (fig. 2a). For RANTES, there was a trend towards an increase in protein concentrations in patients (fig. 2b) but this did not reach statistical significance $(\mathrm{p}=0.08)$.

In order to identify the cellular source of MCP-1, the only chemokine found in this study to be significantly elevated in BALF, cell-associated MCP-1 protein was determined in cytocentrifuge specimens of BAL cells from four patients with sarcoidosis. Strong, uniform expression of MCP-1 was observed in alveolar macrophages. MCP-1 protein was also associated with lymphocytes, however, its expression was limited to approximately one-third of BAL lymphocytes and it was less intensive than in cases of macrophage-associated MCP-1 (data not shown). 

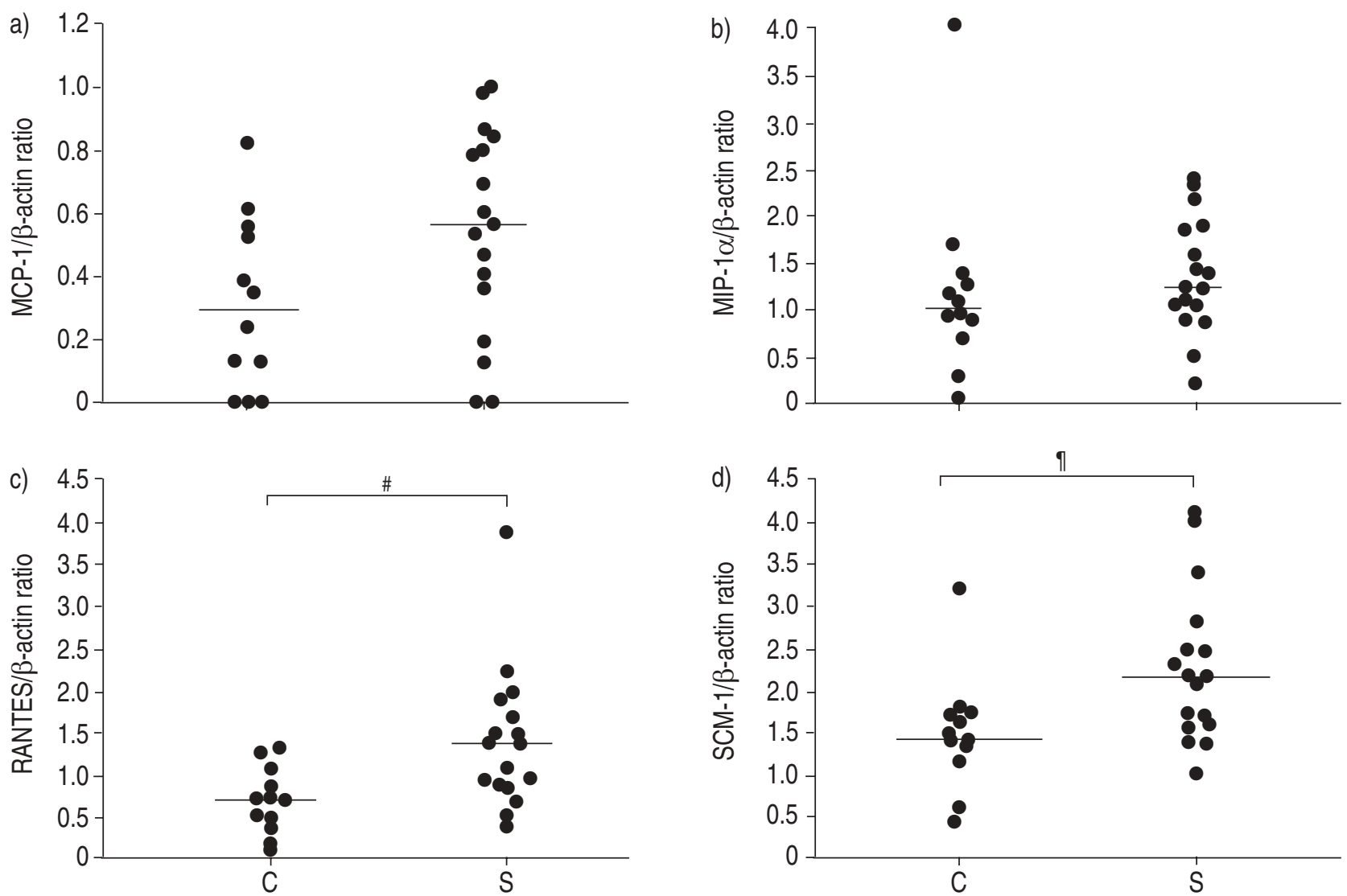

Fig. 1.-Expression of messenger ribonucleic acid (mRNA) for the chemokines a) monocyte chemoattractant protein (MCP)-1, b) monocyte inflammatory protein (MIP)- $1 \alpha$, c) RANTES (regulated on activation, T-cell expressed and secreted) and d) single cysteine motif (SCM)-1 $\alpha$ in unseparated bronchoalveolar cells from control subjects $(\mathrm{C}, \mathrm{n}=12)$ and patients with sarcoidosis $(\mathrm{S}, \mathrm{n}=17)$. The graph shows the values of the ratio chemokine/ $\beta$-actin. The data are presented as optical density ratios of individual examined subjects, the lines represent median values in the groups. Where there are significant differences between the groups. ${ }^{\#}: \mathrm{p}=0.01 ;{ }^{\top}: \mathrm{p}=0.02$.

Chemokine protein expression and the clinical course of sarcoidosis

MCP-1 protein levels were increased in patients with chest radiographic stage 2 compared to patients with stage 1 disease (stage $1(\mathrm{n}=35) 9.8 \pm 3.7 \mathrm{pg} \cdot \mathrm{mL}^{-1}$; stage $\left.2(\mathrm{n}=17) 40.5 \pm 7.8 \mathrm{pg} \cdot \mathrm{mL}^{-1} ; \mathrm{p}=0.003\right)$. Furthermore, MCP-1 BALF protein levels paralleled the clinical course of the disease: MCP-1 levels at presentation in patients whose disease was persistent or recurrent after 2 yrs (categories 3 and 4), were increased by comparison with levels in patients with disease resolution (categories 1 and 2) (categories 3 and $4(\mathrm{n}=14) 26.7 \pm 9.5 \mathrm{pg} \cdot \mathrm{mL}^{-1}$; categories 1 and 2 $\left.(\mathrm{n}=40) 10.3 \pm 3.5 \mathrm{pg} \cdot \mathrm{mL}^{-1} ; \mathrm{p}=0.01\right)$.

Relationship between chemokine expression and $B A L$ cell numbers

Expression of mRNA for the chemokines RANTES and SCM- $1 \alpha$ correlated with BALF lymphocyte numbers (fig. 3). Chemokine mRNA expression was also increased when subjects with an increased proportion of BAL lymphocytes ( $>10 \%$ of BALF cells) were compared to subjects with a low $(\leqslant 10 \%)$ BALF lymphocyte count (RANTES, $\mathrm{p}=0.02 ; \mathrm{SCM}-1 \alpha, \mathrm{p}=0.01$ ). An association was also observed between RANTES and SCM- $1 \alpha$ mRNA, both absolute and relative number of $\mathrm{CD} 4+$ lymphocytes $(\mathrm{p}<0.01)$ and also between these chemokines and $\mathrm{CD} 4 / \mathrm{CD} 8+$ ratio $(\mathrm{p}<0.01)$. MCP-1 protein levels correlated with lavage lymphocyte numbers $(\mathrm{p}=0.02)$ and were elevated in subjects with a higher proportion $(>10 \%)$ of BALF lymphocytes $(p=0.001)$. For RANTES, there was a trend towards an association between protein concentrations and BALF lymphocyte numbers but this did not attain significance. Protein data for SCM-1 $\alpha$ were unavailable. Correlation was also tested between chemokine mRNA/protein data and the percentage and total number of bronchoalveolar macrophages, neutrophils and eosinophils, but no association was found (data not shown).

\section{Discussion}

Accumulation of macrophages and lymphocytes in the alveoli of patients with sarcoidosis results from the interplay between cell adhesion molecules, chemokine ligands and receptors [3, 4]. The present study concentrated on the determination of mRNA and, 

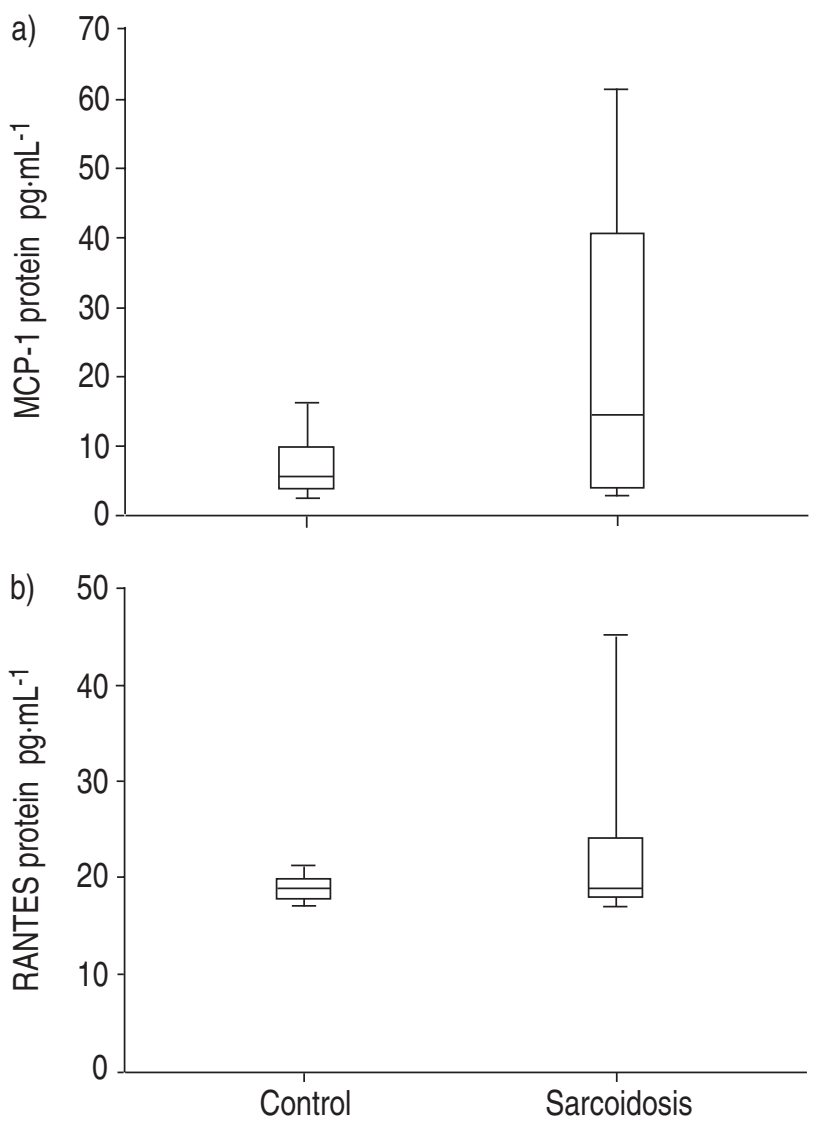

Fig. 2.-Concentrations of chemokine proteins in bronchoalveolar lavage fluid of control subjects and of patients with sarcoidosis. a) monocyte chemoattractant protein (MCP)-1 and b) RANTES (regulated on activation, T-cell expressed and secreted). The data are presented as whisker box plots; the box represents the 25 th to 75 th percentiles, the median is indicated by a bar across the box, the whiskers on each box represent the 10th-90th percentiles. a) $\mathrm{p}=0.02$ and $\mathrm{b}$ ) $\mathrm{p}=0.08$ controls versus sarcoidosis

where possible, also of protein expression of four members of the CCL and XCL chemokine subgroups, the major candidates for mononuclear cell attraction to the lung. The CC chemokines, RANTES and MCP-1, were found to be upregulated in patients with sarcoidosis and elevation of mRNA for SCM- $1 \alpha(\mathrm{C}$ chemokine) was also observed. Chemokine upregulation was most apparent in patients in whom the disease progressed and was associated with lymphocyte alveolitis.

Most prominent were the findings regarding MCP1. MCP-1 expression has been studied in BALF in interstitial lung disease, but until recently predominantly in fibrosing alveolitis [14-15] rather than in sarcoidosis [16]. Increased MCP-1 protein levels in unconcentrated lavage fluid of 60 sarcoidosis patients from this study complement a report of elevated MCP-1 in concentrated BAL of 27 patients with sarcoidosis [17]. Recently, an increase in MCP-1 was reported in serum samples from sarcoidosis patients $[18,19]$. The current authors speculate that systemic MCP-1 levels probably reflect the total granulomatous burden in the body, while BALF levels may better reflect lung involvement. Localisation of cell-associated MCP-1 protein to alveolar macrophages is in agreement with this interpretation. In the context of the above discussions on the role of bronchoalveolar MCP-1 protein, it is interesting to report a marked elevation of MCP-1 protein in BALF of the patients in this study with radiographic stage 2 disease and also in more advanced (i.e. persistent and recurrent) disease. Upregulation of MCP-1 in disease and in its more advanced forms was detected in parallel both in mRNA and in protein levels, although the increase of MCP-1 mRNA in patients just did not reach statistical significance. However, the presence of chemokine protein is necessary for its chemoattractant function and, therefore, the present data on a significant increase of MCP-1 protein levels and its relationship to disease course are relevant in vivo.

The current observations add to previous reports about upregulation of RANTES mRNA and cellassociated protein based on the study of smaller patient numbers [20-22]. Combining localisation of cell-associated RANTES expression predominantly to macrophages [20] with the current data on its BALF levels, it is conceivable that RANTES is indeed secreted from its producer cells into the bronchoalveolar space. However, despite the finding of parallel increase of RANTES both in mRNA and protein levels, the elevation of RANTES protein did not attain significance. IIDA et al. [21] have reported an increase of protein levels in concentrated BALF samples of 40 sarcoidosis patients. It is, therefore, possible that the assay used for RANTES measurements in this study was too sensitive to the dilution factor. This explanation is supported by a recent report [22], a "high-sensitive" ELISA kit for detection of RANTES in unconcentrated BALF was employed. Alternatively, the observed discrepancies in significance between RANTES mRNA and protein assays may be due to possible effects of post-transcriptional and post-translational regulation mechanisms including release and metabolism of RANTES protein [23]. The complexity of the translation process, and the presence of further modifying factors such as storage of the protein or its possible intracellular degradation, may cause a less than straightforward relationship between intracellular mRNA and protein in the BAL fluid. Despite the above constraints, it is important that the direction of changes was the same at both (protein and mRNA) levels and it was in agreement with previous reports [20-22, 24].

MIP-1 $\alpha$ expression has been reported to be increased in sarcoid alveolar macrophages [25]. However, the current authors and others [21] could not detect MIP-1 $\alpha$ protein in BALF from sarcoidosis patients. The MIP-1 $\alpha$-specific ELISA used in this study had an adequate lower detection limit and in ongoing experiments was able to detect considerable amounts of the chemokine protein in bronchoalveolar cell-culture supernatants. These data, together with the finding that MIP- $1 \alpha$ mRNA was present but not upregulated in BALF cells from the patients in this study, suggest that MIP- $1 \alpha$ does not contribute substantially to leucocyte recruitment into the bronchoalveolar compartment in sarcoidosis.

By contrast with the three $\mathrm{CC}$ chemokines discussed 

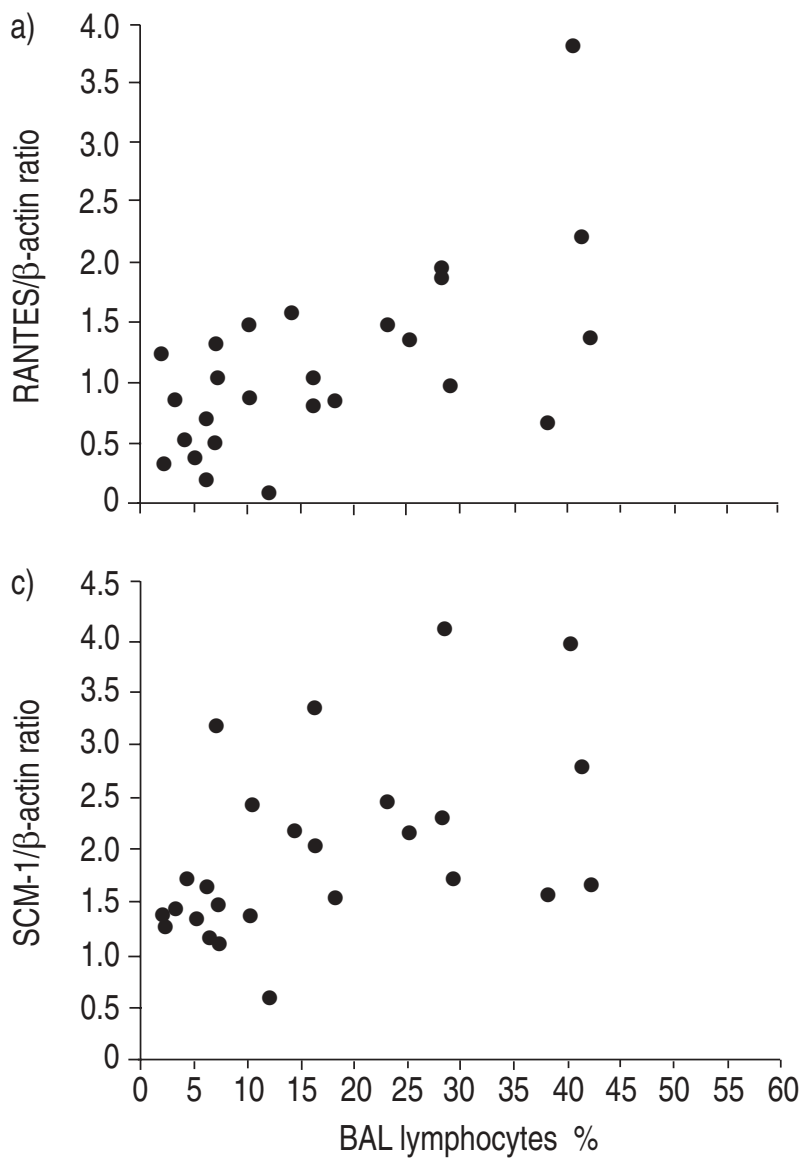

b)

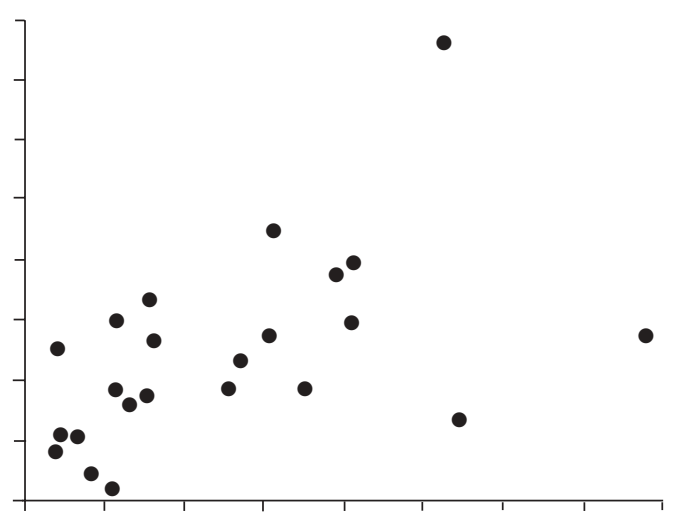

d)

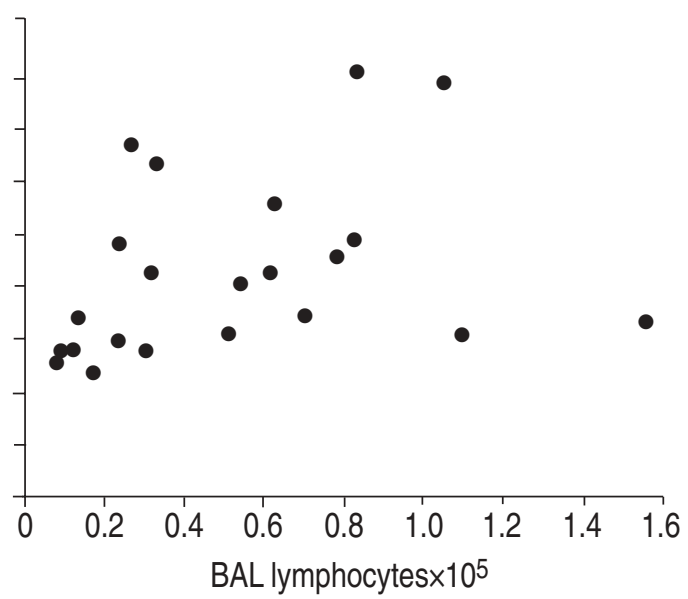

Fig. 3.-Relationship between lymphocytes in bronchoalveolar lavage (BAL) fluid (BALF) and messenger ribonucleic acid (mRNA) expression for chemokines RANTES (regulated on activation, T-cell expressed and secreted) and single cysteine motif (SCM)-1 $\alpha$. a) RANTES versus relative number of BALF lymphocytes; $\mathrm{r}_{\mathrm{B}}=0.593, \mathrm{p}=0.001$. b) RANTES versus absolute number of BALF lymphocytes; $r_{s}=0.607, p=0.002$. c) $S C M-1 \alpha$ versus relative number of BALF lymphocytes; $r_{s}=0.572, p=0.002$. d) $S C M-1 \alpha$ versus absolute number of BALF lymphocytes; $r_{s}=0.571, p=0.004$. The correlations were calculated using all available values of relative $(n=26)$ and absolute $\left(n=23^{\#}\right)$ number of BAL lymphocytes. "\#: in three subjects the total BAL cell number was not available.

above, there are still limited data on the tissue expression of the novel C chemokine, SCM-1 $\alpha[26,27]$. The current findings of SCM- $1 \alpha$ mRNA upregulation in bronchoalveolar cells of sarcoidosis patients extend the data on SCM-1 $\alpha$ expression in human pathology to interstitial lung diseases. SCM- $1 \alpha$ (XCL-1) is a chemoattractant for T-lymphocytes (CD8+) and natural killer cells $[11,28]$. SCM- $1 \alpha$ upregulation together with the relationship between mRNA expression and BALF lymphocyte numbers suggests that XCL-1 may be another chemokine involved in lymphocyte migration to the lung in vivo. However, future detailed studies are needed to better define the role of this single member of the $\mathrm{C}$ chemokine subgroup in the development of alveolitis in sarcoidosis, particularly by identification of its cell source.

Importantly, this study has indicated that chemokine expression in BALF can be associated with clinical course in sarcoidosis. In patients with more advanced disease (assessed after 2 yrs), RANTES, SCM- $1 \alpha$ and MCP-1 mRNA expression at presentation tended to be higher than in patients in whom the disease resolved spontaneously. MCP-1 protein levels at presentation were markedly higher in patients with chest radiographic stage 2 and also in patients, in whom the disease persisted or recurred after 2 yrs. These findings suggest a possible practical exploitation of chemokine measurements in BALF as surrogate markers for assessing likely progression and monitoring of disease course. Both the presented data and the need to reflect a practical point [29] implicate MCP-1 protein measured in unconcentrated BALF to be a suitable candidate marker.

Recently, it was proposed that the chemokines IP10 (CXCL-10) and RANTES act together in regulating the inflammatory infiltrate of sarcoid lesions [30]. The data from this and other studies [16-18, 21, 29] suggest that a wider spectrum of attractant and activating chemokines may contribute to cell migration and activation processes ongoing both locally and systemically in sarcoidosis. It is possible that distinct sets of chemokines, complemented by an array of CC and $\mathrm{C}$ receptors, may be involved in different phases of the disease process. The question of relative contribution of individual chemokines could not be addressed at this stage, nor were the authors able to analyse chemokine ligand-receptor interactions.

Further studies are warranted to address yet 
unanswered issues with emphasis on evaluation of practical applicability of these findings for longitudinal evaluation of patients with pulmonary sarcoidosis.

\footnotetext{
Acknowledgements. The authors would like to thank B. Hutyrová, J. Zlámal and V. Lošt'áková for providing clinical details. They would also like to thank A. Vévodová for providing technical assistance and F. Mrázek for help with preparation of table 1 .
}

\section{References}

1. Newman LS, Rose CS, Maier LA. Sarcoidosis. $N$ Engl J Med 1997; 336: 1224-1234.

2. Homolka J, Müller-Quernheim J. Increased interleukin 6 production by bronchoalveolar lavage cells in patients with active sarcoidosis. Lung 1993; 171: 173-183.

3. Keane MP, Standiford TJ, Strieter RM. Chemokines are important cytokines in the pathogenesis of interstitial lung disease. Eur Respir J 1997; 10: 11991202.

4. Matsukawa A, Lukacs NW, Hogaboam CM, Chensue SW, Kunkel SL III. Chemokines and other mediators. 8. Chemokines and their receptors in cell-mediated immune responses in the lung. Microsc Res Tech 2001; 53: 298-306.

5. Mackay CR. Chemokines-immunology's high impact factors. Nature Immunol 2001; 2: 95-101.

6. Agostini C, Adami F, Semenzato G. New pathogenetic insights into the sarcoid granuloma. Curr Opin Rheumatol 2000; 12: 71-76.

7. Zlotnik A, Yoshie O. Chemokines: a new classification system and their role in immunity. Immunity 2000; 12 : 121-127.

8. Agostini C, Chilosi M, Zambello R, Trentin L, Semenzato G. Pulmonary immune cells in health and disease: lymphocytes. Eur Respir J 1993; 6: 1378-1401.

9. Schall TJ, Bacon KB. Chemokines, leukocyte trafficking and inflammation. Curr Opin Immunol 1994; 6: 865-873.

10. Yoshida $\mathrm{T}$, Imai $\mathrm{T}$, Takagi $\mathrm{S}$, et al. Structure and expression of two highly related genes encoding SCM-1/ human lymphotactin. FEBS Lett 1996; 395: 82-88.

11. Hedrick JA, Zlotnik A. Lymphotactin. Clin Immunol Immunopathol 1998; 87: 218-222.

12. Huninghake GW, Costabel U, Ando M, et al. ATS/ ERS/WASOG statement on sarcoidosis. Sarcoidosis statement committee. American Thoracic Society/ European Respiratory Society/World Association of Sarcoidosis and Other Granulomatous Disorders. Sarcoidosis Vasc Diffuse Lung Dis 1999; 16: 149-173.

13. Petrek M. Analysis of chemokine gene expression in lung cells by polymerase chain reaction. Acta Univ Palacki Olomuc Fac Med 1999; 142: 127-134.

14. Antoniades HN, Neville-Golden J, Galanopoulos T, Kradin RL, Valente AJ, Graves DT. Expression of monocyte chemoattractant protein 1 mRNA in human idiopathic pulmonary fibrosis. Proc Natl Acad Sci USA 1992; 89: 5371-5375.

15. Iyonaga K, Takeya M, Saita N, et al. Monocyte chemoattractant protein-1 in idiopathic pulmonary fibrosis and other interstitial lung diseases. Hum Pathol 1994; 25: 455-463.

16. Car BD, Meloni F, Luisetti M, Semenzato G, Gialdroni-Grasi G, Walz A. Elevated IL-8 and MCP-1 in the bronchoalveolar lavage fluid of patients with idiopathic pulmonary fibrosis and pulmonary sarcoidosis. Am J Resp Crit Care Med 1994; 149: 655659.

17. Sugiyama Y, Kasahara T, Mukaida N, Matsushima $\mathrm{K}$, Kitamura S. Chemokines in the bronchoalveolar lavage fluid of patients with sarcoidosis. Intern Med 1997; 36: 856-860.

18. Iyonaga $\mathrm{K}$, Suga $\mathrm{M}$, Ichiyasu $\mathrm{H}$, Yamamoto $\mathrm{T}$, Hiraga Y, Ando M. Measurement of serum monocyte chemoattractant protein-1 and its clinical application for estimating the activity of granuloma formation in sarcoidosis. Sarcoidosis Vasc Diffuse Lung Dis 1998; 15: $165-172$.

19. Hashimoto S, Nakayama T, Gon Y, et al. Correlation of plasma monocyte chemoattractant protein-1 (MCP-1) and monocyte inflammatory protein-1alpha (MIP-1alpha) levels with disease activity and clinical course of sarcoidosis. Clin Exp Immunol 1998; 111: 604-610.

20. Petrek M, Pantelidis P, Southcott AM, et al. The source and role of RANTES in interstitial lung disease. Eur Respir J 1997; 10: 1207-1216.

21. Iida K, Kadota J, Kawakami K, et al. Analysis of $\mathrm{T}$ cell subsets and beta chemokines in patients with pulmonary sarcoidosis. Thorax 1997; 52: 431-437.

22. Ziora D, Dworniczak S, Niepsuj G, Krol W, Oklek K. Chemokine RANTES in bronchoalveolar lavage fluid (BAL) from different lung segments indicated by high resolution tomography (HRCT) in patients with sarcoidosis (in Polish). Pneumol Alergol 1999; 67: 525-535.

23. Owais M, Arya SK. Antiviral chemokines: intracellular life of recombinant C-C chemokine RANTES. J Hum Virol 1999; 2: 270-282.

24. Kodama N, Yamaguchi E, Hizawa N, et al. Expression of RANTES by bronchoalveolar lavage cells in nonsmoking patients with interstitial lung diseases. Am J Respir Cell Mol Biol 1998; 18: 526-531.

25. Standiford TJ, Rolfe MW, Kunkel SL, et al. Macrophage inflammatory protein-1 alpha expression in interstitial lung disease. J Immunol 1993; 151: 2852 2863.

26. Wang JD, Nonomura N, Takahara S, et al. Lymphotactin: a key regulator of lymphocyte trafficking during acute graft rejection. Immunology 1998; 95: 56-61.

27. Natori Y, Ou ZL, Yamamoto-Shuda Y, Natori Y. Expression of lymphotactin mRNA in experimental crescentic glomerulonephritis. Clin Exp Immunol 1998; 113: 265-268.

28. Giancarlo B, Silvano S, Albert Z, Mantovani A, Allavena P. Migratory response of human natural killler cells to lymphotactin. Eur J Immunol 1996; 26 : 3238-3241.

29. Semenzato G. Chemotactic cytokines: from molecular level to clinical use. Sarcoidosis Vasc Diffuse Lung Dis 1998; 15: 131-133.

30. D'Ambrosio D, Mariani M, Panina-Bordignon P, Sinigaglia F. Chemokines and their receptors guiding T lymphocyte recruitment in lung inflammation. Am J Resp Crit Care Med 2001; 164: 1266-1275. 